\title{
Abrangência do requisito segurança em certificados de qualidade da cadeia produtiva de alimentos no Brasil
}

\author{
Scope of safety requirement in quality \\ certificates used in food production in Brazil
}

\author{
Ana Paula de Rezende Peretti ${ }^{1}$ \\ Wilma Maria Coelho Araújo²
}

\begin{abstract}
Resumo: Os certificados ou selos de qualidade são utilizados em diversos países, inclusive no Brasil, com o intuito de diferenciar produtos ou unidades de produção de alimentos. São considerados mecanismos de regulação da qualidade, que podem ser concedidos por organismos governamentais, credenciados a eles ou ainda por organizações não governamentais. Os motivos para a certificação são os mais diversos possíveis, destacando-se: demanda de clientes internacionais, imagem dos produtos junto aos clientes, demanda de consumidores mais exigentes ou ainda agregar valor ao produto ou serviço. Os procedimentos para concessão dos certificados variam, especialmente considerando-se a esfera de concessão (âmbito governamental ou associações do setor produtivo). Este trabalho, de caráter exploratório, avaliou a abrangência do requisito segurança em 13 procedimentos de certificação da qualidade identificados na cadeia produtiva de alimentos no Brasil. Constatou-se a predominância da utilização das ferramentas Boas Práticas de Fabricação e Boas Práticas Agrícolas, sendo que o sistema APPCC, ferramenta reconhecida pelo Codex Alimentarius para o gerenciamento de perigos na produção de alimentos é utilizado apenas por apenas 3 dos 13 certificados avaliados.
\end{abstract}

Palavras-chave: Alimentos. Certificados. Qualidade. Selos. Segurança. Perigos.

\begin{abstract}
Quality certificates or seals are used in many countries, including in Brazil, in order to differentiate products or food production plants. They are considered quality regulation mechanisms, which can be given by government agencies, authorized institutions or nongovernmental organizations. The reasons for certification are many, such as: international clients demand, image of the products among the clients, demanding consumers request, or to add value to a product or service. Procedures for getting permission to use these certificates may vary, especially considering if it is given by a governmental or nongovernmental agency. This article, an exploratory study, evaluated the scope of the safety requirement in 13 quality certificate or seals used in food production in Brazil. It was found that most of the certificates use the tools Good Manufacturing Practices and Good Agriculture Practices. Only three of the certificates consider HACCP, tool recognized by Codex Alimentarius for hazard management in food production as requirement.
\end{abstract}

Keywords: Food. Certificates. Quality. Seals. Safety. Hazards.

\section{Introdução}

É crescente a preocupação com a qualidade dos produtos alimentícios, em especial no que se refere à sua segurança, devido ao desenvolvimento de novas tecnologias e à credibilidade dos órgãos responsáveis pela saúde pública. A fim de atender à demanda de clientes internacionais, melhorar a imagem dos produtos junto aos clientes, atender à demanda de consumidores mais exigentes ou ainda agregar valor ao produto ou serviço surgem certificados ou selos de qualidade desenvolvidos por iniciativa do Estado e/ou do setor produtivo. Muitos destes certificados incluem a segurança ou a inocuidade como requisito para certificação.

Tendo em vista o crescente número de certificados ou selos de qualidade veiculados em rótulos ou propagandas de alimentos e a possibilidade destes

\footnotetext{
${ }^{1}$ Mestre em Nutrição Humana, Dissertação aprovada pelo programa de pós-graduação em Nutrição Humana, Departamento de Nutrição, Fundação Universidade de Brasília, Campus Universitário Darcy Ribeiro, Asa Norte, CEP 70910.900, Brasília - DF, Brasil, E-mail: apperetti@ hotmail.com

${ }^{2}$ Doutora em Tecnologia de Alimentos, Departamento de Nutrição, Fundação Universidade de Brasília,

Campus Universitário Darcy Ribeiro, Asa Norte, CEP 70910-900, Brasília - DF, Brasil, E-mail: wilma.araujo@terra.com.br
}

Recebido em 11/3/2008 — Aceito em 8/2/2010

Suporte financeiro: Nenhum. 
mecanismos reduzirem a assimetria de informações sobre a qualidade dos produtos na relação de consumo de alimentos, faz-se necessário analisar o tipo de garantia oferecida ao consumidor por meio destes certificados.

Neste trabalho, de natureza exploratória, pretende-se verificar a abrangência do requisito segurança entre os certificados de qualidade existentes na cadeia produtiva de alimentos que contemplam este atributo como requisito para sua concessão.

\section{Revisão bibliográfica}

A preocupação com a qualidade e seu conceito sofreu adaptações com o desenvolvimento tecnológico e a necessidade crescente de segurança. As principais alterações de características no controle de qualidade e suas formas são apresentadas no Quadro 1.

Na cadeia produtiva de alimentos no Brasil, a implantação de sistemas de gestão da qualidade e a certificação ocorreram em função das exigências do mercado externo e das grandes empresas multinacionais que passaram a exigi-las de seus fornecedores. A relação entre sistema, garantia e controle da qualidade é sistematizada na Figura 1.

O conceito de qualidade em alimentos é construído em função da dinâmica da relação de consumo e envolve o Estado, o setor produtivo e os consumidores. Ablan (2000) considera que a qualidade dos alimentos pode ser analisada sob três categorias distintas: nível

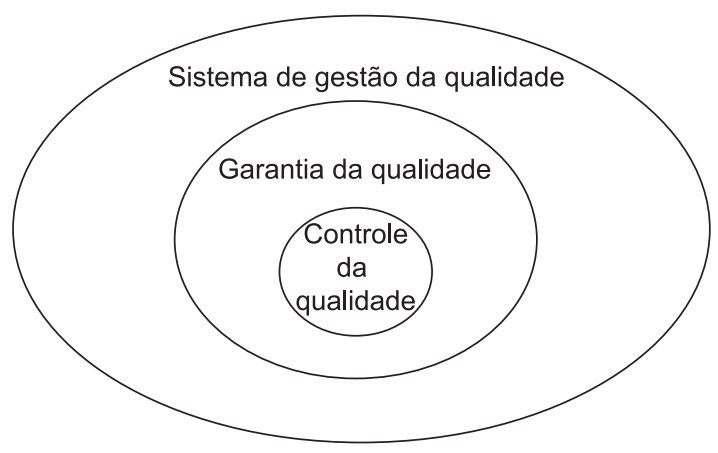

Figura 1. Relação entre sistema de gestão, garantia e controle da qualidade. básico, que inclui características físico-químicas e de inocuidade, que deve ser atingido por qualquer produto alimentício e geralmente é controlado pelo Estado; a qualidade nutricional, que se torna importante a partir da conscientização dos consumidores sobre o efeito da alimentação para a saúde; e os atributos de valor associados aos produtos alimentícios, tais como respeito ao meio ambiente, respeito aos trabalhadores e o respeito às tradições, por exemplo.

Para Kuaye (1995), qualidade é essencialmente a inocuidade dos alimentos seguida por outras características físico-químicas e organoléticas; envolve ainda os atributos nutricionais e higiênico-sanitários. Para estes autores, a segurança do alimento é atributo básico a ser contemplado por qualquer produto e independerá de fatores sociais e econômicos, por se tratar de um indicador objetivo.

A preocupação com a segurança do alimento se intensifica paralelamente ao crescimento da produção e ao desenvolvimento de novas tecnologias. O conceito de segurança do alimento destaca-se entre os demais aspectos qualitativos dos produtos e se relaciona à proteção e à preservação da vida e da saúde humana dos riscos representados por perigos possíveis de estarem presentes nos alimentos. Assim, a segurança do produto depende dos níveis aceitáveis do perigo no alimento, ou seja, do nível de proteção necessário para a saúde do consumidor (PAS, 2004).

Um alimento ou bebida é considerado seguro quando, ao longo de sua cadeia produtiva, são adotadas medidas sanitárias e de higiene efetivas e eficazes, que não permitem a presença de riscos em níveis acima dos tolerados pelo consumidor, sempre e quando os produtos forem usados nas condições indicadas e para os fins a que se destinam.

No âmbito internacional, o interesse e as questões relativas à segurança ocupam lugar de destaque, especialmente nas discussões científicas e tecnológicas e naquelas que subsidiam a concepção de normas e regulamentos para o comércio internacional. A segurança dos alimentos foi reconhecida pela World Health Organization - WHO (2002) e por seus Estados membros como uma prioridade da saúde pública durante a 53 ${ }^{\mathrm{a}}$ World Health Assembly, em maio de 2000. Desta reunião, resultou a elaboração de uma estratégia global de segurança dos alimentos

Quadro 1. Evolução do conceito de controle da qualidade.

\begin{tabular}{|lcc|}
\hline \multicolumn{1}{|c|}{ Época } & Forma de controle & Característica do controle \\
\hline Pré-Revolução Industrial & Artesão & Acompanhamento de todas as etapas \\
Pós-Revolução Industrial & Inspeção & Reativa \\
$1920-30$ & Controle estatístico do processo & Corretiva \\
$1950-60$ & Garantia da qualidade & Preventiva \\
1980 & Gestão da qualidade & Preditiva \\
\hline
\end{tabular}

Fonte: Adaptado Inmetro, 2000. 
a fim de reduzir a incidência de doenças de origem alimentar.

Os atributos de segurança dos alimentos para o comércio internacional são definidos pelo Codex Alimentarius. O Brasil, como país signatário do Codex, utiliza as normas internacionais como referência para as normas brasileiras que norteiam a produção de alimentos, publicadas pela Agência Nacional de Vigilância Sanitária - ANVISA, e pelo Ministério da Agricultura, Pecuária e Abastecimento - MAPA.

A delimitação da atuação destes dois órgãos se dá pela natureza dos produtos. Alimentos de origem animal e seus fabricantes são monitorados pelo Departamento de Inspeção de Produtos de Origem Animal - DIPOA, enquanto as bebidas e vinagres são monitorados pelo Departamento de Inspeção Vegetal - DIV, ambos do MAPA. Os demais produtos e estabelecimentos, a comercialização no ponto de venda, o uso de aditivos, a rotulagem são de competência da Agência Nacional de Vigilância Sanitária - ANVISA.

O direito à aquisição de alimentos seguros é garantido aos consumidores pelo artigo $6^{\circ}$ do Capítulo III do Código de Defesa do Consumidor - CDC (BRASIL, 1990). Da mesma forma, a lei define que a responsabilidade sobre a segurança dos produtos disponibilizados ao consumidor é do fabricante, produtor, construtor, nacional ou estrangeiro, e do importador, que respondem, independentemente da existência de culpa, pela reparação dos danos causados aos consumidores por defeitos decorrentes de projeto, fabricação, construção, montagem, fórmulas, manipulação, apresentação ou acondicionamento de seus produtos, bem como por informações insuficientes ou inadequadas sobre sua utilização e riscos.

Além de responsabilidade civil, a oferta de alimentos seguros também se configura em uma responsabilidade social, uma vez que este conceito está associado a práticas éticas e transparentes em relação à comunidade, aos trabalhadores e às suas famílias, aos fornecedores, aos clientes, ao poder público e ao meio ambiente (INSTITUTO ETHOS, 2003).

A gestão da segurança de alimentos é desempenhada principalmente pelo Estado e pelo setor produtivo, uma vez que a maioria dos consumidores, embora devam participar desta gestão por meio do controle social, ainda não tem conhecimentos suficientes sobre os riscos decorrentes do consumo de alimentos (PAS, 2004).

O papel do Estado na gestão da segurança passou por algumas modificações na última década. Até recentemente, a maioria dos sistemas de regulação da segurança dos alimentos estava fundamentada em definições legais de alimentos inseguros, no recolhimento destes alimentos do mercado e na aplicação de sanções às partes responsáveis. No entanto, este sistema tradicional não atende aos desafios atuais da segurança do alimento, que exige uma abordagem preventiva ao invés de corretiva. $\mathrm{Na}$ última década, houve a transição deste modelo para outro, baseado na análise de riscos, proporcionando uma base preventiva para medidas regulatórias de segurança nos âmbitos internacional e nacional (WHO, 2002).

A análise de riscos é um processo composto pelas etapas de avaliação, gestão ou gerenciamento, e comunicação de riscos. A avaliação de riscos é o processo fundamentado em conhecimentos científicos, que envolve a identificação e a caracterização do perigo, a avaliação da exposição da população ao risco e, finalmente, a caracterização do risco. A comunicação de riscos consiste no intercâmbio interativo de informações e opiniões sobre risco, entre as pessoas responsáveis pela avaliação de risco, pelo gerenciamento de risco, os consumidores e outras partes interessadas.

A gestão ou gerenciamento do risco é o processo de ponderação das distintas opções normativas à luz dos resultados da avaliação de risco e, caso necessário, da seleção e aplicação de possíveis medidas de controle apropriadas, incluídas as medidas de regulamentação (BRASIL, 1999).

Tomando como referência o conceito de segurança do alimento, que trata da proteção e preservação da vida e da saúde humana, dos riscos representados por perigos possíveis de estarem presentes nos alimentos, depreende-se que a gestão da segurança pode ser entendida como a somatória da gestão de riscos e da gestão de perigos.

A gestão de riscos consiste em determinar "como" e "em até que nível" a exposição ao risco pode e deve ser gerenciada, uma vez que o risco zero na produção e transformação de alimentos é impraticável. O conhecimento do risco, da magnitude de seu efeito e das condições que favorecem os agravos e danos à saúde é essencial para a gestão da segurança do consumidor, bem como da saúde pública.

No entanto, a gestão do risco não pode considerar exclusivamente o aspecto da saúde. Outros fatores como o custo do produto seguro, os hábitos de consumo e a disponibilidade de tecnologia também devem ser levados em consideração. Assim, de forma abrangente, somente o Estado pode avaliar imparcialmente a viabilidade e as consequências da introdução de programas e leis que impliquem em ganhos no nível de segurança. Como resultado dessas análises, são geradas medidas de controle sanitário tais como legislação e intensificação da inspeção sanitária, determinação de obrigatoriedade de registro ou certificação de determinado produto ou serviço (SPERS, 2003; PAS, 2004). O setor produtivo é responsável por gerenciar os riscos relacionados aos produtos sob sua responsabilidade. 
A gestão de perigos envolve a determinação de "o quê" deve ser gerenciado. O conhecimento do perigo e de suas características é de extrema importância para uma gestão que visa a saúde do consumidor. São exemplos de gestão de perigos os programas de Boas Práticas, incluindo os Procedimentos Operacionais Padronizados - POP, e o sistema de Análise de Perigos por Pontos Críticos de Controle - APPCC. A relação entre a gestão de riscos e de perigos e as ferramentas de gestão de perigos dentro do controle e garantia da qualidade é apresentada na Figura 2.

Observa-se que a gestão dos riscos à saúde pública gerados na produção e comercialização de alimentos nível macro - é realizada pelo Estado. A gestão de perigos é executada basicamente pelo setor produtivo, que utiliza ferramentas de gestão de perigos tais como as BPF, incluindo o POP, como parte do controle de qualidade do processo de produção, e ainda o sistema APPCC, visando a garantia da qualidade, sobretudo da segurança dos alimentos disponibilizados ao mercado consumidor.

O Estado, como mediador das relações de consumo, atua monitorando a qualidade de produtos e serviços e intervém por meio de regulamentos técnicos ou ações fiscais a fim de preservar a saúde pública. Tal intervenção utiliza-se de indicadores para a realização de programas de monitoramento de produtos pela Vigilância Sanitária e também pelo Inmetro. A Vigilância Sanitária por meio da ANVISA e dos órgãos estaduais e municipais desenvolve três programas de monitoramento da qualidade dos

Gestão da segurança $=$

Gestão de riscos + Gestão de perigos

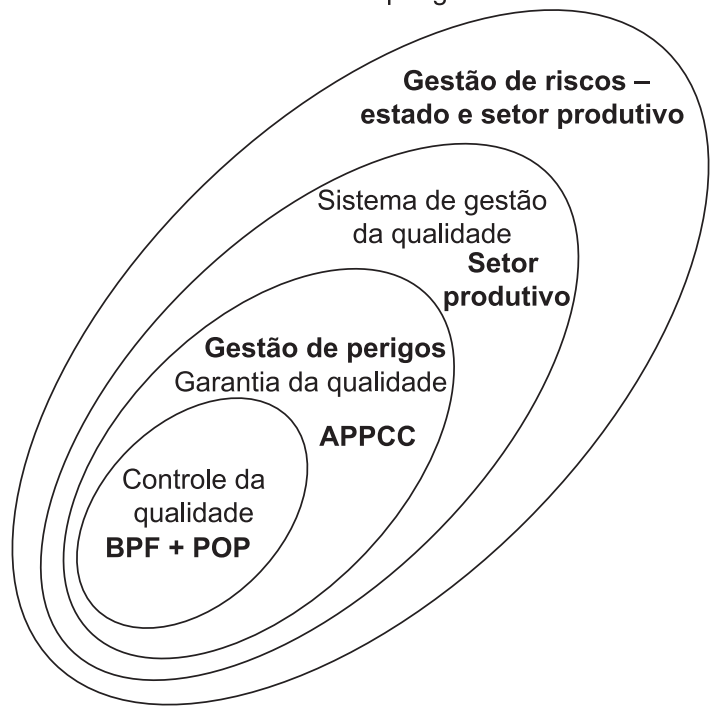

Figura 2. Gestão da segurança, gestão de riscos e gestão de perigos. produtos: o Programa Nacional de Monitoramento da Qualidade Sanitária de Alimentos - PNMQSA, o Programa de Monitoramento de Resíduos de Agrotóxicos em Alimentos - PARA e o Programa de Análise de Resíduos de Medicamentos Veterinários em Alimentos Expostos ao Consumo - PAMVet. O Inmetro realiza o Programa de Análise de Produtos, que inclui produtos alimentícios.

A partir dos resultados do PNMQSA, observa-se o baixo grau de adequação dos produtos analisados aos padrões legais. Das 24 categorias de alimentos pesquisadas pelo PNMQSA desde 2000, apenas quatro (16\%) apresentaram padrão sanitário $100 \%$ de acordo com os padrões sanitários vigentes (BRASIL, 2005b.).

Os resultados do PARA de 2003 indicam um percentual de resíduos irregulares de agrotóxicos da ordem de 31,9\% entre os resíduos detectados em amostras de alface, banana, batata, cenoura, laranja, maçã, mamão, morango e tomate. Dentro desta percentagem de irregularidade, o maior problema é o uso indiscriminado de agrotóxicos nos alimentos, uma vez que $88,9 \%$ dos resíduos irregulares não eram autorizados para o alimento pesquisado. Os $11,1 \%$ restantes encontravam-se acima dos valores admitidos para o resíduo (BRASIL, 2004).

O PAMVet tem como objetivo a identificação de resíduos de medicamentos veterinários e atualmente, por questões de validação de metodologia, estes resíduos têm sido analisados somente em leite UHT e em pó. Segundo os resultados obtidos até o momento, a presença de antimicrobianos detectadas no leite está abaixo dos limites aceitáveis, enquanto que $9 \%$ do total de amostras apresentaram resíduos de antiparasitários acima do limite aceitável (BRASIL, 2005a). No caso do Programa de Análise de Produtos, do Inmetro, das 29 categorias de alimentos pesquisadas de 1996 a 2004, apenas quatro categorias apresentaram resultados $100 \%$ conformes (INMETRO, 2005).

De posse destes indicadores, os órgãos reguladores podem criar ações de controle sanitário como os regulamentos técnicos específicos para determinado tipo de alimento - Boas Práticas de Fabricação para o palmito, sal iodado, gelados comestíveis; ou ainda determinar a certificação compulsória ou voluntária de determinados tipos de alimentos. Tais ações são consideradas mecanismos formais de regulação da qualidade (SPERS, 2003).

Além das ações implantadas pelo Estado, o setor produtivo também desenvolve ações de regulação da qualidade, entre as quais a concessão de certificados de qualidade aos produtos ou aos estabelecimentos. Esta ação merece destaque uma vez que, fora do âmbito governamental, não está sujeita a nenhum tipo de controle no que diz respeito aos mecanismos de avaliação de conformidade empregados, aos tipos de requisitos utilizados para certificação ou à forma de 
apresentação destes certificados ou selos nos rótulos ou propagandas.

\section{Material e método}

Trata-se de uma pesquisa exploratória (MALHOTRA, 2001; SANTOS, 2002), uma vez que visa sistematizar as informações disponíveis sobre os processos de certificação na cadeia produtiva de alimentos no Brasil e avaliar a abrangência da segurança como requisito de certificação.

Foram pesquisados os certificados de qualidade existentes na cadeia produtiva de alimentos no Brasil, concedidos por órgãos do governo ou por iniciativa de associações de produtores, associações médicas e de empresas isoladamente. Tendo em vista o número demasiado de processos identificados, optou-se por delimitar a população de estudo segundo dois critérios.

O primeiro critério de inclusão é o de que a certificação tenha como objeto um produto, processo ou sistema de gestão na cadeia produtiva de alimentos. Por certificação de produto e processo, entende-se a avaliação de conformidade envolvendo ferramentas tais como ensaios (análises) e auditorias a fim de comprovar o atendimento a requisitos pré-definidos. A certificação de sistema de gestão é entendida como a avaliação do modelo de gestão da qualidade ou gestão ambiental adotado por determinada organização, por meio da realização de auditorias. Por esse critério, exclui-se, por exemplo, a certificação profissional para manipuladores e supervisores de alimentos, criada pelo Instituto de Hospitalidade e em fase de implantação no Sistema Brasileiro de Avaliação de Conformidade.

O segundo critério de inclusão é o de que o certificado de qualidade deve ter abrangência nacional, ou seja, um produto ou processo do segmento de alimentos é elegível independentemente da região onde se encontra a unidade de produção. Assim, ficam excluídos aqueles de abrangência regional como, por exemplo, o selo de origem do Vale dos Vinhedos utilizado para vinhos produzidos na região montanhosa do Rio Grande do Sul.

O terceiro critério é o de que a concessão do certificado deve abranger requisitos relacionados à segurança de alimentos. O conceito de segurança utilizado nesta análise é o que trata da proteção e preservação da vida e da saúde humana dos riscos representados por perigos possíveis de estarem presentes nos alimentos.

A pesquisa envolveu levantamento bibliográfico e análise documental para coleta de dados. A coleta de dados foi realizada no período de julho de 2003 a novembro de 2004 em sites de busca, livros, jornais, revistas indexadas e não indexadas da área de alimentos e também em rótulos de produtos alimentícios.
As informações sobre os requisitos dos processos de certificação selecionados foram obtidas a partir de consultas aos sites das associações, órgãos públicos e organizações não governamentais responsáveis pelo processo de certificação. Quando as informações disponíveis não eram suficientes, recorreu-se a consultas via $e$-mail ou telefone junto à entidade certificadora.

A fim de sistematizar as informações coletadas sobre os diferentes processos de certificação e facilitar a leitura, foi criado um quadro resumo com os certificados de qualidade objetos de estudo.

Neste quadro, cada certificado é identificado quanto ao ano de lançamento no Brasil, tipo de mecanismo de regulação da qualidade (formal, se no âmbito governamental; informal, caso ocorra fora dele), objeto de certificação (tipo de alimento, tipo de estabelecimento), organismo certificador (órgão governamental, associações de produtores, organismos credenciados pelo Inmetro, associações médicas), normas ou regulamentos de referência para certificação (normas são documentos emitidos por uma organização não governamental e regulamentos técnicos são documentos oficiais, publicados pelo Poder Público) e a ferramenta de avaliação de conformidade envolvida.

Os certificados foram avaliados quanto ao tipo de perigo alvo e a ferramenta de gestão de perigos (Boas Práticas Agrícolas, Boas Práticas de Fabricação, Procedimentos Operacionais Padronizados e Análise de Perigos por Pontos Críticos de Controle), incluída como requisito para certificação.

\section{Resultados e discussão}

O Quadro 2 resume os certificados contemplados neste estudo: 13 certificados de qualidade que consideram, entre os requisitos de certificação, aspectos relacionados à segurança do alimento. Do total de certificados analisados, 38\% (5/13) ocorrem no âmbito governamental e, portanto, são considerados mecanismos formais de regulação da qualidade dos alimentos. Os demais (62\% 8/13) são considerados mecanismos informais: acontecem por iniciativa do setor produtivo ou de associações médicas, sem intervenção do Estado para sua concessão. Os mecanismos informais de certificação apresentam como desvantagem o fato de, muitas vezes, apresentarem critérios redundantes, que podem gerar falsas interpretações por parte dos consumidores sobre o real benefício na aquisição do produto certificado.

O carimbo do SIF - para produtos de origem animal, o selo do Inmetro - para cestas de alimentos, e a certificação de produtos orgânicos $(60 \%$ - 3/5) são os certificados que ocorrem em âmbito governamental; compulsórios por determinação do Estado. Tais 


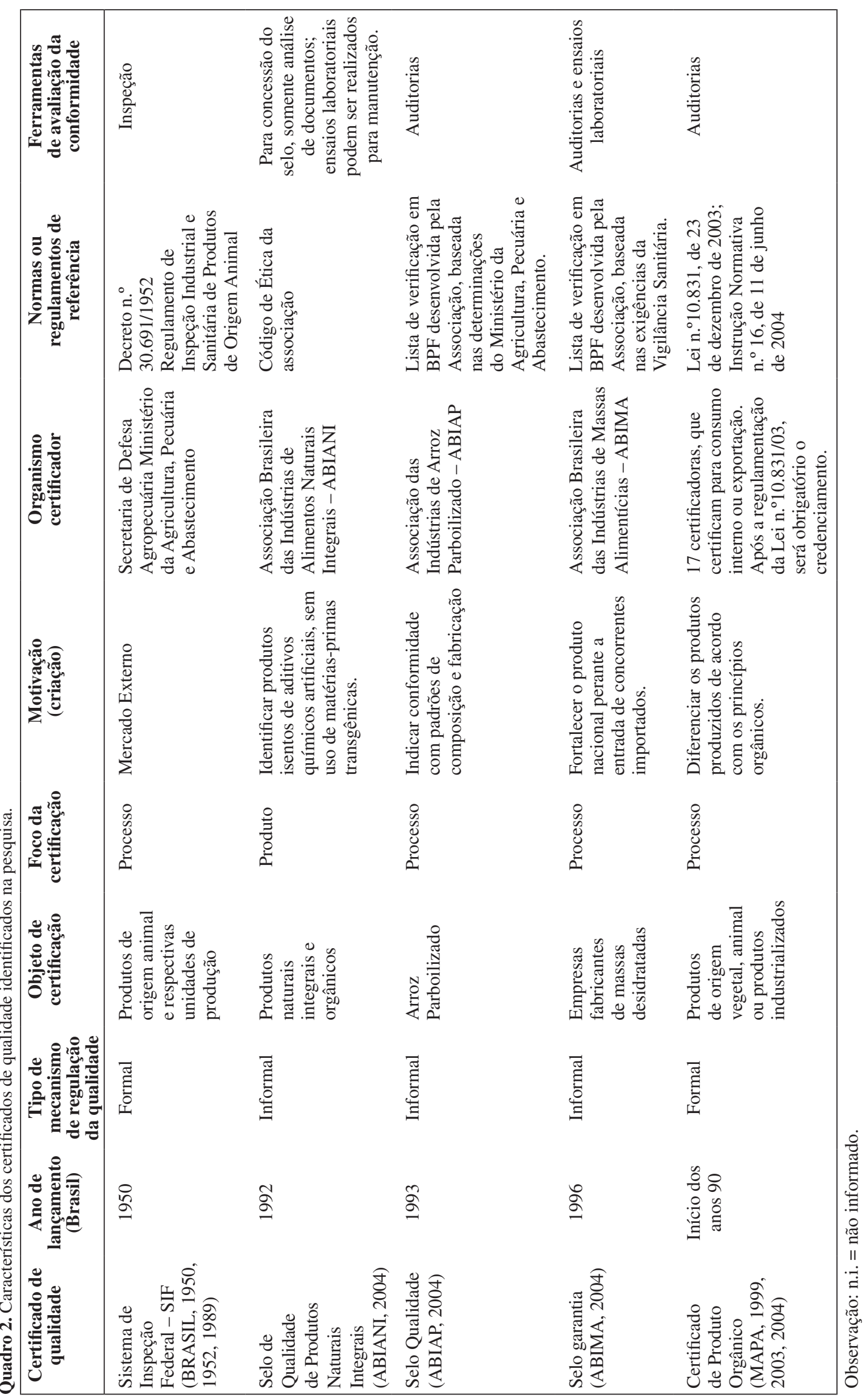




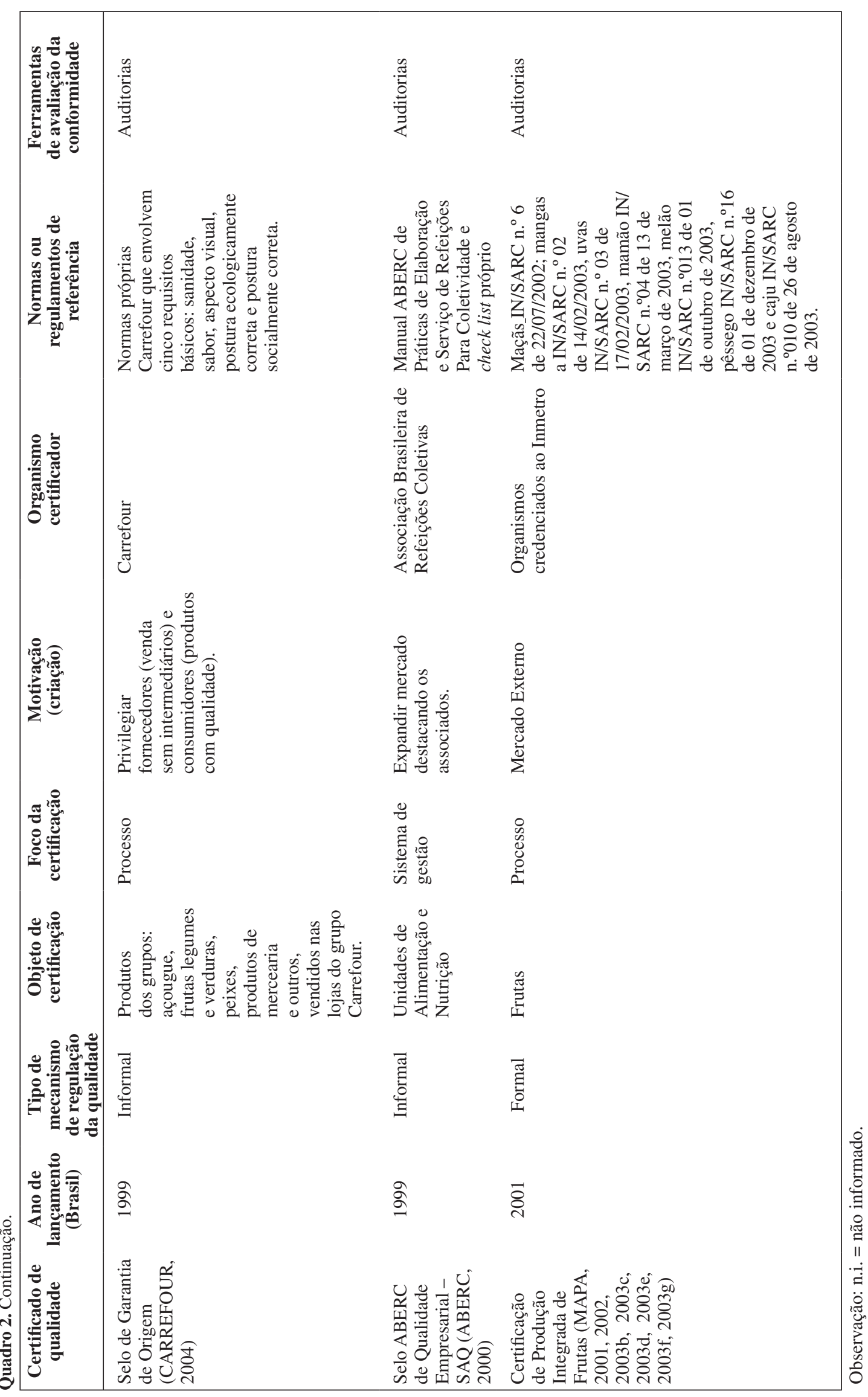




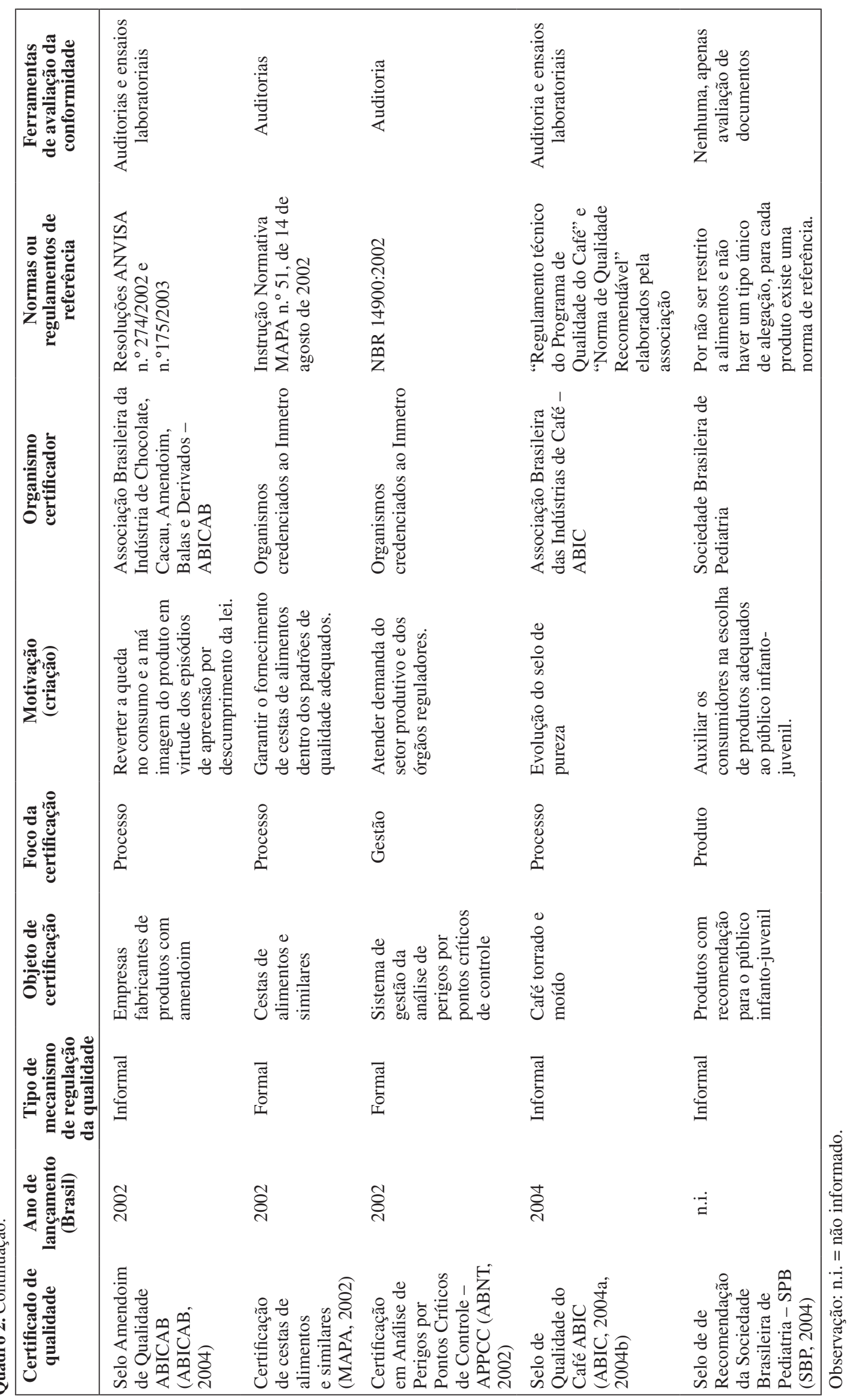


certificados são concedidos ou por um órgão da administração pública - como, por exemplo, o do SIF ou por organismos credenciados ao Inmetro - cestas de alimentos e produtos orgânicos. Os outros dois são de certificação voluntária, assim como todos os certificados classificados como mecanismos informais.

Observa-se que o foco da certificação indica coerência com o atual conceito de controle da qualidade, de caráter eminentemente preventivo: para 77\% (10/13) dos certificados é o processo de produção; para 8\% (1/13), o sistema de gestão; e para $15 \%(2 / 13)$, o produto final.

O Quadro 3 apresenta os 13 certificados de qualidade que contemplam a inocuidade bem como os demais requisitos considerados em cada processo de certificação. Em três deles (23\% - 3/13), a inocuidade, apesar de classificada como atributo básico, pode ser considerada um atributo de valor, uma vez que não se refere ao cumprimento de normas mínimas de qualidade e sim, à ausência do uso de aditivos e/ou agroquímicos - como se observa para os produtos orgânicos, selo Associação Brasileira das Indústrias de Alimento Naturais Integrais - ABIANI e selo da Sociedade Brasileira de Pediatria - SBP.

Além da inocuidade, outros atributos básicos são contemplados por 38\% (5/13) dos certificados. Observa-se, no entanto, que a inocuidade é requisito exclusivo para apenas um dos certificados analisados selo Amendoim de Qualidade. Ademais, dentre os certificados, o carimbo do SIF merece destaque uma vez que sua presença indica que o produto está sujeito à inspeção federal. Entretanto, os instrumentos legais sobre a obrigatoriedade de aplicação de ferramentas de gestão de perigos - Portarias n. ${ }^{\circ} 368$ (BRASIL, 1997) e 46 (BRASIL, 1998) - determinam que a garantia da qualidade é de responsabilidade do fabricante.

Apenas 15\% (2/13) agregam atributos básicos e de valor, e outros 15\% agregam atributos básicos e outros atributos, mais especificamente de sistemas de gestão. Somente um certificado contempla atributos básicos, de valor e outros (sistema de gestão), o selo de Qualidade do Café ABIC, uma evolução do selo de pureza criado pela mesma associação. A rastreabilidade é contemplada por 69\% (9/13) dos certificados, sempre associada à inocuidade, uma vez que as ferramentas de gestão de perigos - BPA, BPF e APPCC - incluem este princípio.

No Quadro 4 são apresentados os certificados de qualidade e a abrangência da gestão de perigos adotada por eles. Somente o carimbo do SIF, a certificação de cestas de alimentos e a certificação em APPCC incluem como requisito para certificação o sistema de Análise de Perigos por Pontos Críticos de Controle - APPCC, sistema reconhecido internacionalmente pelo Codex Alimentarius para o gerenciamento da inocuidade dos alimentos. Todos estes certificados ocorrem em âmbito governamental.
Pode-se verificar que 23\% (3/13) dos certificados incluem as Boas Práticas Agrícolas - BPA, no entanto, o certificado PIF é o único que contempla exclusivamente esta ferramenta de gestão de perigos. Para os produtos orgânicos e para os produtos com Garantia de Origem Carrefour, o uso de agroquímicos não é permitido, assim como o uso de matérias-primas transgênicas (CARREFOUR, 2004; BRASIL, 2003). No caso da PIF, o uso de agroquímicos é permitido, desde que balanceado com a utilização de técnicas e métodos biológicos de forma a minimizar os perigos químicos. Exceto o selo de Garantia de Origem Carrefour, os demais ocorrem em âmbito governamental e se relacionam à produção de alimentos para o mercado externo.

As Boas Práticas de Fabricação - BPF são consideradas em 77\% (10/13) dos processos de certificação; dentre eles, metade $(5 / 10)$ requer somente esta ferramenta, que inclui os POPs, para certificação. Todos ocorrem por iniciativa de associações de produtores. O cumprimento das BPF é um procedimento mínimo para a obtenção de um alimento seguro.

Dois certificados focam a ausência de perigos químicos na etapa de industrialização - selo ABIANI e selo da Sociedade Brasileira de Pediatria, ambos classificados como mecanismos informais de regulação da qualidade. Adicionalmente, o selo ABIANI não permite a adição de matérias-primas geneticamente modificadas, assim como os certificados para produtos orgânicos e o Selo de Garantia de Origem Carrefour.

O selo Amendoim de Qualidade exige exclusivamente a inocuidade como requisito para concessão do certificado. Trata-se de um atributo mínimo de qualidade exigido pela legislação sanitária e, portanto, não se configura como um diferencial, mas como uma obrigação do fabricante. A utilização de um selo na embalagem de um produto de amendoim, seguindo os critérios em questão, não necessariamente indica uma qualidade superior à do produto sem o selo, que, a priori, também está sujeito às mesmas exigências legais.

A criação deste selo, assim como a do regulamento técnico de Boas Práticas específico para este tipo de produto, foram respostas do setor produtivo e do poder público, respectivamente, após a apreensão de produtos de amendoim com níveis de aflatoxina superiores aos permitidos pela legislação, apontados pelo monitoramento da qualidade de produtos, realizado pelo Inmetro (2000). Neste caso, houve atuação do Estado e do setor produtivo na gestão dos riscos associados ao consumo de amendoim, porém de forma a prevenir que este fato volte a ocorrer e não de se antecipar ao problema. De modo geral, os certificados avaliados preconizam a aplicação das $\mathrm{BPF}$, incluindo POP como ferramenta de gestão de riscos (Figura 3). 


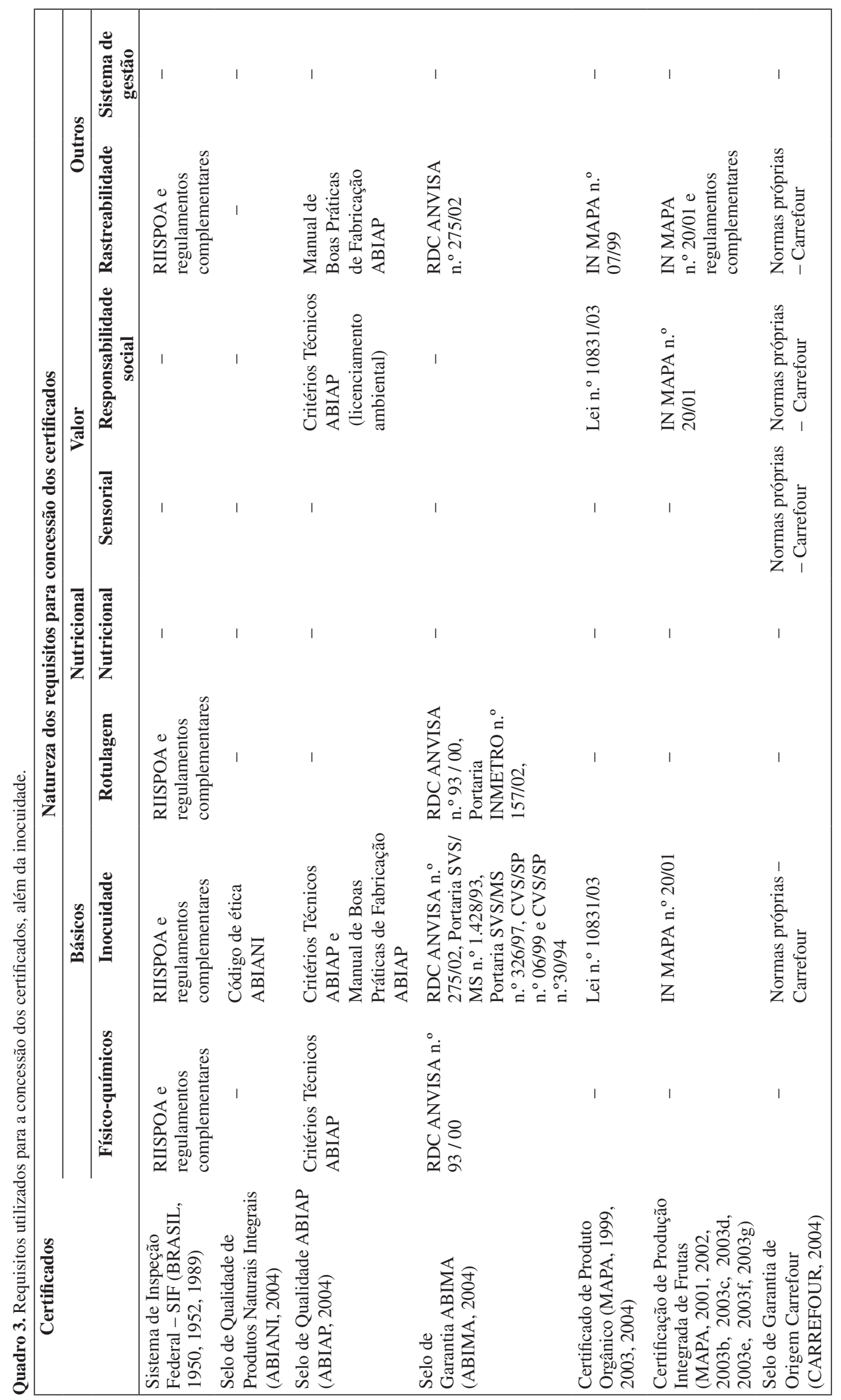




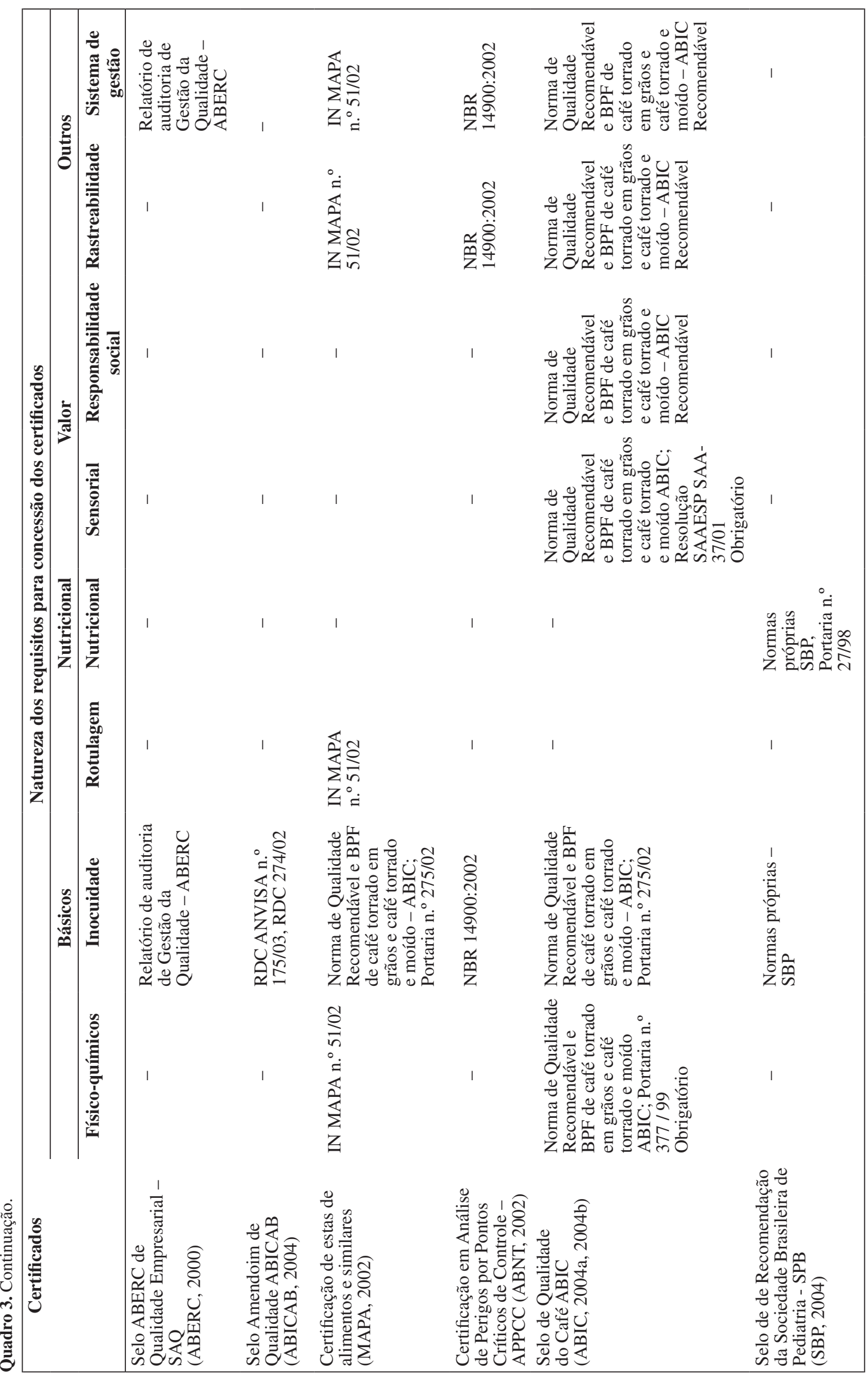


Quadro 4. Abrangência da segurança nos certificados de qualidade.

\begin{tabular}{|c|c|c|c|c|c|c|c|c|}
\hline \multirow[t]{2}{*}{ Certificados } & \multicolumn{3}{|c|}{ BPA } & \multicolumn{3}{|c|}{ BPF } & \multirow[t]{2}{*}{ POP } & \multirow[t]{2}{*}{ APPCC } \\
\hline & $\begin{array}{l}\text { Perigos } \\
\text { físicos }\end{array}$ & $\begin{array}{c}\text { Perigos } \\
\text { químicos }\end{array}$ & $\begin{array}{c}\text { Perigos } \\
\text { biológicos }\end{array}$ & $\begin{array}{l}\text { Perigos } \\
\text { físicos }\end{array}$ & $\begin{array}{c}\text { Perigos } \\
\text { químicos }\end{array}$ & $\begin{array}{c}\text { Perigos } \\
\text { biológicos }\end{array}$ & & \\
\hline $\begin{array}{l}\text { Sistema de Inspeção Federal - SIF } \\
\text { (BRASIL, 1950, 1952, 1989) }\end{array}$ & & & & $\times$ & $x$ & $x$ & $x$ & $x$ \\
\hline $\begin{array}{l}\text { Selo de Qualidade de Produtos } \\
\text { Naturais Integrais (ABIANI, 2004) }\end{array}$ & & & & & $x$ & & & \\
\hline $\begin{array}{l}\text { Selo de Qualidade ABIAP } \\
\text { (ABIAP, 2004) }\end{array}$ & & & & $x$ & $x$ & $x$ & $x$ & \\
\hline $\begin{array}{l}\text { Selo de Garantia ABIMA } \\
\text { (ABIMA, 2004) }\end{array}$ & & & & $x$ & $x$ & $x$ & $x$ & \\
\hline $\begin{array}{l}\text { Certificado de Produto Orgânico } \\
\text { (MAPA, 1999, 2003, 2004) }\end{array}$ & $x$ & $x$ & $x$ & $x$ & $x$ & $x$ & & \\
\hline $\begin{array}{l}\text { Selo de Garantia de Origem } \\
\text { Carrefour (CARREFOUR, 2004) }\end{array}$ & $x$ & $\times$ & $\times$ & $x$ & $x$ & $x$ & $x$ & \\
\hline $\begin{array}{l}\text { Selo ABERC de Qualidade } \\
\text { Empresarial - SAQ (ABERC, 2000) }\end{array}$ & & & & $x$ & $x$ & $\times$ & $x$ & \\
\hline $\begin{array}{l}\text { Certificação de Produção Integrada de } \\
\text { Frutas (MAPA, 2001, 2002, 2003b, } \\
\text { 2003c, 2003d, 2003e, 2003f, 2003g) }\end{array}$ & $x$ & $\times$ & $\times$ & & & & & \\
\hline $\begin{array}{l}\text { Selo Amendoim de Qualidade } \\
\text { ABICAB (ABICAB, 2004) }\end{array}$ & & & & $x$ & $x$ & $x$ & $x$ & \\
\hline $\begin{array}{l}\text { Certificação de estas de alimentos e } \\
\text { similares (MAPA, 2002) }\end{array}$ & & & & $x$ & $x$ & $x$ & $x$ & $x$ \\
\hline $\begin{array}{l}\text { Certificação em Análise de Perigos } \\
\text { por Pontos Críticos de Controle - } \\
\text { APPCC (ABNT, 2002) }\end{array}$ & & & & $x$ & $x$ & $x$ & $x$ & $x$ \\
\hline $\begin{array}{l}\text { Selo de Qualidade do Café ABIC } \\
\text { (ABIC, 2004a, 2004b) }\end{array}$ & & & & $x$ & $x$ & $x$ & $x$ & \\
\hline $\begin{array}{l}\text { Selo de Recomendação da Sociedade } \\
\text { Brasileira de Pediatria - SPB } \\
\text { (SBP, 2004) }\end{array}$ & & & & & $x$ & & & \\
\hline
\end{tabular}

Gestão da segurança $=$

Gestão de riscos + Gestão de perigos

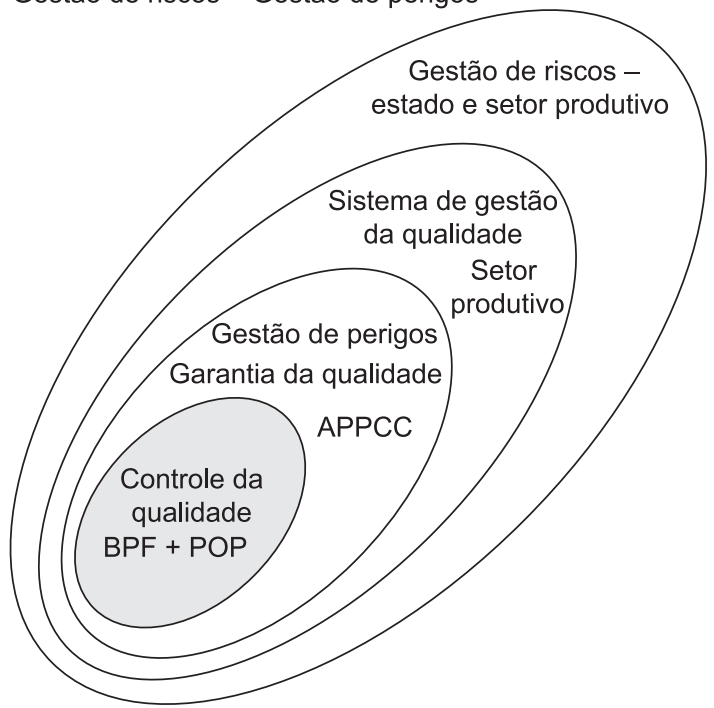

Figura 3. Abrangência da gestão de perigos nos certificados avaliados.

\section{Conclusão}

Os resultados obtidos indicam que, entre os certificados analisados, predomina a adoção das ferramentas Boas Práticas de Fabricação e Boas Práticas Agrícolas. Tais ferramentas são as bases para a produção de alimentos seguros e para a adoção de um sistema APPCC.

Entre os certificados analisados, não foi observada a existência de ensaios como ferramenta única de avaliação de conformidade, o que indica a incorporação do caráter preventivo ao controle de qualidade de produtos alimentícios. Esta ferramenta sempre ocorre adicionalmente às auditorias.

Os certificados concedidos por associações de produtores merecem louvor por promover melhorias no respectivo segmento, no entanto, a utilização destes certificados no rótulo dos produtos pode gerar dúvidas quanto aos benefícios do produto com selo. Dada a diversidade de certificados para expressar a conformidade a padrões legais, o consumidor pode interpretar que um produto certificado tem qualidade 
superior aos demais, quando todos deveriam cumprir as mesmas determinações legais. Desta forma, seria conveniente, a bem dos consumidores, a unificação dos selos para um modelo único de certificado de conformidade, a fim de atestar a qualquer alimento, o cumprimento de determinações legais.

O selo de Garantia ABIMA, que se autointitulava um selo de garantia e não de qualidade, foi extinto pela própria associação, após 8 anos de existência por entender que o setor já atingiu um grau de conformidade no atendimento aos padrões legais. O programa de melhoria da qualidade das massas continua por meio do Programa de Garantia ABIMA, no entanto, sem a utilização de selo nos rótulos dos produtos.

Um ponto relevante a ser questionado é a inexistência de análise de riscos para a criação de certificados de qualidade que ocorrem fora do âmbito governamental. Os certificados específicos - café, arroz parboilizado, massas secas - foram criados em função de fatores econômicos e não necessariamente considerando o impacto destes produtos na saúde pública.

A gestão da segurança na cadeia produtiva de alimentos ainda tem muito a se desenvolver, tanto por parte dos órgãos reguladores que precisam se antecipar aos problemas sanitários envolvidos com estes produtos e, principalmente, por parte do setor produtivo que precisa se conscientizar de que este é um atributo básico e fundamental para uma relação justa de consumo.

\section{Referências}

ABLAN, E. Políticas de calidad en el sistema agroalimentario español. Agroalimentaria, n. 10, p. 63-72. 1992.

ASSOCIAÇÃO BRASILEIRA DE NORMAS TÉCNICAS. Sistema de gestão da análise de perigos por pontos críticos de controle - Segurança dos alimentos. 2002.

ASSOCIAÇÃO BRASILEIRA DAS INDÚSTRIAS DE ALIMENTOS NATURAIS E INTEGRAIS - ABIANI. Selo de Qualidade, Estatuto, Código de Ética e Proposta. Disponível em: <http://www.abiani.com. br>. Acesso em: 08 jul. 2004.

ASSOCIAÇÃO BRASILEIRA DAS INDÚSTRIAS DE ARROZ PARBOILIZADO - ABIAP. Selo de Qualidade. Disponível em: <http://www.abiap.com.br>. Acesso em: 20 maio 2004.

ASSOCIAÇÃO BRASILEIRA DAS INDÚSTRIAS DE CHOCOLATE, CACAU, AMENDOIM, BALAS E DERIVADOS - ABICAB. A entidade: associados por região. Disponível em: <http://www.abicab.org.br/ index_home.htm>. Acesso em: 12 set. 2004.

ASSOCIAÇÃO BRASILEIRA DAS INDÚSTRIAS DE MASSAS ALIMENTÍCIAS - ABIMA. Selo de Garantia. Disponível em: <http://www.abima.com. br>. Acesso em: 18 jun. 2004.
ASSOCIAÇÃO BRASILEIRA DE REFEIÇÕES COLETIVAS - ABERC. Manual ABERC de boas práticas de elaboração de serviço de refeições para coletividade. São Paulo, 2000.

ASSOCIAÇÃO BRASILEIRA DOS PROFISSIONAIS DA QUALIDADE DE ALIMENTOS - PROFIQUA. Manual de Análise de perigos por pontos críticos de controle-APPCC. Campinas, 1995.

ASSOCIAÇÃO DAS INDÚSTRIAS DE CAFÉ - ABIC. Norma de Qualidade Recomendável e Boas Práticas de Fabricação de Cafés Torrados em Grãos e Cafés Torrados e Moídos. 2004. Emissão inicial 28/04/04 e revisada em 04/06/04. Disponível em: <http://www. abic.com.br>. Acesso em: 03 set. 2004a.

ASSOCIAÇÃO DAS INDÚSTRIAS DE CAFÉ - ABIC. Programa de Qualidade do Café: Selo de Qualidade. Passo-a-Passo. 2004. Disponível em: <http://www.abic. com.br>. Acesso em: 23 nov. 2004b.

BRASIL. Lei n. 10.831, de 23 de dezembro de 2003. Dispõe sobre a agricultura orgânica e dá outras providências. 2003. Disponível em: <http: //www.agricultura.gov. br>. Acesso em: 13 jun. 2004.

BRASIL. Lei n. ${ }^{\circ}$ 1283, de 18 de dezembro de 1950. Dispõe sobre a inspeção industrial sanitária dos produtos de origem animal. 1950. Disponível em: <http://www. agricultura.gov.br>. Acesso em: 13 jun. 2004.

BRASIL. Decreto n. ${ }^{0}$ 30691, de 29 de março de 1952. Aprova o regulamento de inspeção industrial e sanitária de produtos de origem animal. 1952. Disponível em: $<$ http://www.agricultura.gov.br>. Acesso em: 13 jun. 2004.

BRASIL. Lei n ${ }^{\circ} \mathbf{7 . 8 8 9}$, de 23 de novembro de 1989. Dispõe sobre a inspeção sanitária industrial dos produtos de origem animal e dá outras providências. 1989. Disponível em: <http://www.agricultura.gov.br>. Acesso em: 13 jun. 2004.

BRASIL. Lei no 8.078, de 11 de setembro de 1990. Código de Defesa do Consumidor. 1990. Disponível em: <http:// www.in.gov.br>. Acesso em: 02 set. 2003.

BRASIL. Resolução ANVISA n 274, de 15 de outubro de 2002. Aprova o Regulamento Técnico Sobre Limites Máximos de Aflatoxinas Admissíveis no Leite, no Amendoim, no Milho. 2002. Disponível em: <http:// www.anvisa.gov.br/alimentos/bpf.htm >. Acesso em: 28 fev. 2005.

BRASIL. Resolução ANVISA no 175, de 04 de julho de 2003. Dispõe sobre o Regulamento Técnico de Boas Práticas de Fabricação para Estabelecimentos Industrializadores de Amendoins Processados e Derivados e a Lista de Verificação das Boas Práticas de Fabricação para Estabelecimentos Industrializadores de Amendoins Processados e Derivados. 2003. Disponível em: <http:// www.anvisa.gov.br/alimentos/bpf.htm >. Acesso em: 28 fev. 2005.

BRASIL. ANVISA. Resolução $\mathbf{n}^{\circ} \mathbf{1 7}$, de 30 de abril de 1999. Regulamento Técnico que estabelece as diretrizes básicas para avaliação de risco e segurança dos alimentos. 1999. Disponível em: <http://www.anvisa.gov.br/ alimentos >. Acesso em: 28 fev. 2005.

BRASIL. ANVISA. RDC $\mathbf{n}^{\mathbf{0}} \mathbf{2 7 5}$, de 21 de outubro de 2002. Dispõe sobre o Regulamento Técnico de 
Procedimentos Operacionais Padronizados aplicados aos Estabelecimentos Produtores/Industrializadores de Alimentos e a Lista de Verificação das Boas Práticas de Fabricação em Estabelecimentos Produtores/ Industrializadores de Alimentos. 2002. Disponível em: <http://www.anvisa.gov.br/alimentos/bpf.htm>. Acesso em: 28 fev. 2005.

BRASIL. ANVISA. Relatório Anual 2003 - Programa de Avaliação de Resíduos de Agrotóxicos em Alimentos. 2004. Disponível em: <http://www.anvisa.gov.br>. Acesso em: 4 mar. 2005.

BRASIL. ANVISA. Relatório 2002-2003 do Programa de Análise de Resíduos de Medicamentos Veterinários em Alimentos de Origem Animal - PAMVet Monitoramento de resíduos em leite exposto ao consumo. Gerência Geral de Alimentos - Gerência de Ações de Ciência e Tecnologia de Alimentos. 2005a. Disponível em: <http://www.anvisa.gov.br>. Acesso em: 04 mar. 2005.

BRASIL. ANVISA. Programa de Monitoramento da Qualidade Sanitária de Alimentos. 2005b. Disponível em: <http://www.anvisa.gov.br>. Acesso em: 04 mar. 2005.

BRASIL. Ministério da Agricultura. Portaria no 269, de 17 de novembro de 1988. Dispõe sobre as normas de identidade, qualidade, embalagem e apresentação do arroz e revoga a Portaria nº 205/1981. 1988. Disponível em: <http://www.agricultura.gov.br>. Acesso em: 13 jun. 2004.

BRASIL. Ministério da Agricultura. Portaria no 368, de 04 de setembro de 1997. Aprovar o Regulamento Técnico sobre as condições Higiênico-Sanitárias e de Boas Práticas de Fabricação para Estabelecimentos Elaboradores/Industrializadores de Alimentos. 1997. Disponível em: <http://www.agricultura.gov.br>. Acesso em: 28 fev. 2005.

BRASIL. Ministério da Agricultura. Portaria MAA nº 46, de 16 de março de 1998. Instituir o Sistema de Análise de Perigos e Pontos Críticos de Controle - APPCC a ser implantado, gradativamente, nas indústrias de produtos de origem animal sob o regime do serviço de inspeção federal - SIF, de acordo com o manual genérico de procedimentos. 1998. Disponível em: <http://www. agricultura.gov.br>. Acesso em: 28 fev. 2005.

BRASIL. Ministério da Agricultura. Instrução Normativa $\mathbf{n}^{\mathbf{0}}$ 7, de 17 de maio de 1999. Dispõe sobre normas para a produção de produtos orgânicos vegetais e animais. 1999. Disponível em: <http://www.agricultura.gov.br>. Acesso em: 26 out. 2003.

BRASIL. Ministério da Agricultura. Instrução Normativa $\mathbf{n}^{\mathbf{0}}$. 20, de 27 de setembro de 2001. Aprova as diretrizes gerais para a Produção Integrada de Frutas - DGPIF e as Normas Técnicas Gerais para a Produção Integrada de Frutas - NTGPIF. 2001. Disponível em: <http://www. agricultura.gov.br>. Acesso em: 26 out. 2003.

BRASIL. Ministério da Agricultura. Instrução Normativa n. 16, de 11 de junho de 2004. Estabelece os procedimentos a serem adotados, até que se concluam os trabalhos de regulamentação da Lei $\mathrm{n}^{\circ} 10.831$, de 23 de dezembro de 2003, para registro e renovação de registro de matérias primas e produtos de origem animal e vegetal, orgânicos, junto ao Ministério da Agricultura, Pecuária e Abastecimento - MAPA. 2004. Disponível em: <http: //www.agricultura.gov.br>. Acesso em: 14 jun. 2004.

BRASIL. Ministério da Agricultura. Instrução Normativa SDA n $^{0}$ 51, de 14 agosto de 2002. Aprovar o Regulamento Técnico que estabelece os Requisitos Mínimos Operacionais das Instalações e Equipamentos na Produção de Cestas de Alimentos e Similares, anexo a esta Instrução Normativa. 2002. Disponível em: <http:// www.inmetro.gov.br>. Acesso em: 01 set. 2004.

BRASIL. Ministério da Agricultura. Instrução Normativa MAPA nº 08, de 11 de junho de 2003. Aprova o Regulamento Técnico de Identidade e de Qualidade para a Classificação do Café Beneficiado Grão Cru. 2003a. Disponível em: <http://www.agricultura.gov. br>. Acesso em: 26 jul. 2004.

BRASIL. Ministério da Agricultura. Instrução Normativa/

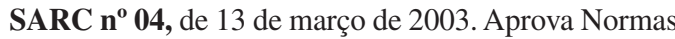
Técnicas específicas para produção integrada de mamão. 2003b. Disponível em: <http://www.inmetro.gov.br> Acesso em: 26 out. 2003.

BRASIL. Ministério da Agricultura. Instrução Normativa/ SARC n⿳010, de 26 de agosto de 2003. Aprova Normas Técnicas específicas para produção integrada de caju. 2003c. Disponível em: <http://www.inmetro.gov.br>. Acesso em: 26 out. 2003.

BRASIL. Ministério da Agricultura. Instrução Normativa/ SARC n⿳11, de 18 de setembro de 2003. Aprova Normas Técnicas específicas para produção integrada de uva. 2003d. Disponível em: <http://www.inmetro.gov.br>. Acesso em: 26 out. 2003.

BRASIL. Ministério da Agricultura. Instrução Normativa/ SARC n⿳12, de 18 de setembro de 2003. Aprova Normas Técnicas específicas para produção integrada de manga. 2003e. Disponível em: <http://www.inmetro. gov.br>. Acesso em: 26 out. 2003.

BRASIL. Ministério da Agricultura. Instrução Normativa/ $\operatorname{SARC~n}^{\mathbf{0} 13}$, de 01 de outubro de 2003. Aprova Normas Técnicas específicas para produção integrada de melão. 2003f. Disponível em: <http://www.inmetro.gov.br>. Acesso em: 26 out. 2003.

BRASIL. Ministério da Agricultura. Instrução Normativa/ SARC n⿳16, de 01 de dezembro de 2003. Aprova Normas Técnicas específicas para produção integrada de pêssego. 2003g. Disponível em: <http://www.inmetro. gov.br>. Acesso em: 26 out. 2003.

BRASIL. Ministério da Agricultura. Instrução Normativa/ SARC n $\mathbf{n}^{\mathbf{1}} \mathbf{1 7}$, de 02 de dezembro de 2003. Aprova Normas Técnicas específicas para produção integrada de maçã. 2003h. Disponível em: <http://www.inmetro.gov.br>. Acesso em: 26 out. 2003.

BRASIL. Ministério da Saúde. Portaria n 1428, de 26 de novembro de 1993. Aprova, na forma dos textos anexos, o "Regulamento Técnico para Inspeção Sanitária de Alimentos", as "Diretrizes para o Estabelecimento de Boas Práticas de Produção e de Prestação de Serviços na Área de Alimentos" e o "Regulamento Técnico para o Estabelecimento de Padrão de Identidade e Qualidade (PIQ's) para Serviços e Produtos na Área de Alimentos". Determina que os estabelecimentos relacionados à área de alimentos adotem, sob responsabilidade técnica, as 
suas próprias Boas Práticas de Produção e/ou Prestação de Serviços, seus Programas de Qualidade, e atendam aos PIQI's para Produtos e Serviços na Área de Alimentos. 1993. Disponível em: <http://www.anvisa.gov.br>. Acesso em: 28 fev. 2005.

BRASIL. Ministério da Saúde. Portaria SVS no 326, de 30 de julho de 1997. Aprova o Regulamento Técnico sobre "Condições Higiênico-Sanitárias e de Boas Práticas de Fabricação para Estabelecimentos Produtores/ Industrializadores de Alimentos". 1997. Disponível em: $<$ http://www.anvisa.gov.br/alimentos/bpf.htm>. Acesso em: 28 fev. 2005.

BRASIL. Ministério da Saúde. Portaria SVS no 377, de 26 de abril de 1999. Aprova o Regulamento Técnico referente a Café Torrado em Grão e Café Torrado e Moído. 1999. Disponível em: <http://www.anvisa.gov. br>. Acesso em: 10 nov. 2004.

CARREFOUR. O que é Garantia de Origem? Disponível em: <http://www.carrefour.com.br>. Acesso em: 14 dez. 2004.

CODEX ALIMENTARIUS COMISSION - CAC. Guidelines for the design, operation, assessment and accreditation of food import and export inspection and certification. 1997. Disponível em: <http://www.codexalimentarius. net>. Acesso em: 28 fev. 2005.

INMETRO. A História da Qualidade e o Programa Brasileiro da Qualidade e Produtividade. Rio de Janeiro: INMETRO/SENAI, 2000.

INMETRO. Cartilha sobre Avaliação da Conformidade. Brasília, 2002. Disponível em: <http://www.inmetro. gov.br>. Acesso em: 18 jul. 2004.

INMETRO. Produtos analisados. Disponível em: <http:// www.inmetro.gov.br>. Acesso em: 04 mar. 2005.

INSTITUTO ETHOS. Práticas Empresariais de Responsabilidade Social: relações entre os princípios Global Compact e os indicadores Ethos de responsabilidade social. São Paulo: Instituto Ethos, 2003.

KUAYE, A. Análise de perigos e pontos críticos de controle e a qualidade dos alimentos. Revista Nacional da Carne, v. 237, p. 32-37, 1995.
MAKIYA, I. K.; ROTONDARO, R. G. Integração entre os sistemas GMP / HACCP / ISO 9000 nas indústrias de alimentos. Higiene Alimentar, v. 16, n. 99, p. 46-50, ago. 2002.

MALHOTRA, N. K. Pesquisa de Marketing: uma orientação aplicada. 3 ed. Porto Alegre: Bookman, 2001.

OLIVEIRA, A. M.; MASSON, M. L. Terminologia e definições utilizadas nos sistemas da qualidade e segurança alimentar. Boletim da Sociedade Brasileira de Ciência e Tecnologia de Alimentos, v. 37, n. 1, p. 52-57, jan.-jun 2003.

ORGANIZAÇÃO PANAMERICANA DA SAÚDE - OPAS; INSTITUTO PANAMERICANO DE PROTEÇÃO DE ALIMENTOS - INPPAZ. HACCP: instrumento essencial para inocuidade dos alimentos. Buenos Aires: INPPAZ, 2001.

PRÓ-AMENDOIM. Pró-amendoim - Projeto ABICAB. Disponível em: <http://www.proamendoim.com.br>. Acesso em: 13 out. 2004.

PROGRAMA ALIMENTO SEGURO - PAS. Análise de Riscos na Gestão da Segurança de Alimentos. Brasília, DF: Ações Especiais PAS Análise de Riscos, 2004.

SANTOS, A. R. Metodologia científica: a construção do conhecimento. Rio de Janeiro: DPeA, 2002.

SENAI. Programa Alimentos Seguros. Disponível em: <http://www. alimentos.senai.br>. Acesso em: 01 out. 2004.

SOCIEDADE BRASILEIRA DE PEDIATRIA - SBP. A instituição. Disponível em: <http://www.sbp.com.br>. Acesso em: 19 jul. 2004.

SPERS, E. E. Mecanismos de regulação da qualidade e segurança em alimentos. 2003. 155 f. Tese (Doutorado em Administração) - Faculdade de Economia, Administração e Contabilidade, Universidade de São Paulo, São Paulo, 2003.

WORLD HEALTH ORGANIZATION - WHO. WHO global strategy for food safety: safer food for better health. Genebra, 2002. Disponível: <http://www.who. int/foodsafety/publications /general/global_strategy/ en/>. Acesso em: 19 nov. 2004. 